\title{
Integration of Human Exercise Science and Occupation of Health
}

\section{Manager}

\author{
Guangzhou Li *, Bangshi Guo, Jianyu Liu, Chengliang Wu \\ School of Sports and Health, Chongqing Three Gorges University, China \\ *liguangzhou@126.com
}

\begin{abstract}
Keywords: Human Exercise Science; Health Management; applied technology University; vocational education
\end{abstract}

\begin{abstract}
Integration of industries, universities and research institutions is an important approach to cultivate applied talents for specialized applied technology colleges and an effective way to address enterprises' need for high-quality technologists. This paper studies the inevitability, feasibility and existing problems of the integration of Human Exercise Science and the profession with the occupation of health manager in the process of talent cultivation so as to achieve the win-win situation of firms, universities and students.
\end{abstract}

\section{Introduction}

As the reform of Ministry for National Education gets increasingly specific, more than 600 regular higher educational institutions of China have transformed to applied technology-based types. This reform, focusing on talent cultivation mode, complies with the current contradiction between China's urgent need of applied talents under the social and economical development and the severe graduate recruitment. The key to this reform is the genuine integration of industries, universities and research institutions and the training and cultivation of high-level competent talents, during which the connection of education and employment should be emphasized.

Social need for talents and individual career orientation determine the training objective, major task and development direction of education and then significantly guide teaching contents, teaching methods and talent cultivation. The lack of appropriate vocational education in academic education may make it difficult to meet the new social requirements in talent cultivation objective $\&$ mode, teaching method \& content, curriculum system and other aspects, which may force firms to increase the training cost on new employees and cause the waste of educational resources.

China has released standards for new occupation health manager, which accords with the cultivation objective of Human Exercise Science in some ways makes it feasible to connect professional talent training in human exercise science education and the occupation of health manager. Such connection provides favorable conditions for the talent cultivation mode based on the educational principle of "dual-certificate".

Inevitability of the dynamic integration of occupational qualification authentication system and higher academic certificate education

Occupational qualification certificate system is an important part of labor employment system and a special form of national examination system. It complies with the national-formulated occupational skill standards or qualification requirements and makes objective, fair, scientific and 
normative evaluation and identification on labors' skill standards or qualifications through government-approved evaluation and identification institutions. Qualifiers are awarded relevant national job qualification certificates. It is a strategic measure in Chinese human resource development to conduct occupational skill identification and carry out the occupational qualification authentication system. It is significant for China to improve the quality of the workforce, promote the construction of the labor market and boost the social and economic development.1

So far, the higher academic certificate education and occupational qualification authentication system of China haven't been effectively connected. Occupational qualification authentication and higher academic certificate education are unbalanced originally and the demarcation of the relationship between academic certificate education and occupational education is not very clear both in theory and practice. There are various reasons for this and higher education itself is relevant. A lot of universities haven't sufficiently realized that professional teaching mode should be constructed within the frame of occupational qualification. Besides, teaching disciplinarity is dense; teaching contents, textbooks, methods and evaluation criterion cannot meet the requirements of occupational education satisfactorily; the connection between the cultivation objective of occupation or course and occupational qualification certificate is poor; the practical teaching level of teachers and teaching attachments lag behind the requirements of the existing occupational certificate education;2 qualification authentication of the society's high-skilled professional personnel to introduce them to the university classroom teaching hasn't been solved radically, etc. Therefore, the disconnection between higher academic certificate education and occupational qualification authentication system becomes increasingly severe and is very likely to be ignored.

In November 1994, the Fifth Meeting of the Third Session of the Fourteenth Central Committee of the CPC first stipulated clearly in the Decision on Several Issues in Building Socialist Market Economy that China should attach equal importance to two certificates: academic certificate and occupational qualification certificate. In June 1999, in the Decisions to Deepen Education Reform and Promote Quality Education released by the Central Committee of the Communist Party of China and the State Council, implementation of the dual-certificate system (academic certificate and occupational qualification certificate) in the entire society was emphasized again. According to the expectation, after a certain period of exploration and reform, the connection between the occupational certificate authentication system and higher education should be strengthened; on the other hand, the frame system of national occupational qualifications should be established step by step and the correspondence between occupational qualification and educational qualification should become more and more specific. Meanwhile, the employment entrance system and occupational qualification authentication system should be further perfected. Under the national occupational qualification system, the equivalent effect of occupational qualification certificate and academic certificate on labor, personnel and salary system will be realized gradually. For this reason, occupational qualification authentication system should be emphasized in academic education system, and students should be encouraged to participate in all kinds of social trainings. 3 The requirements of vocational knowledge and skill requirements should be better reflected in curriculum provisions and teaching contents. Undergraduates' practical manipulative ability should be enhanced based on the full integration of theory and practice, so that students who are about to serve the society can "obtain from what is learnt and implement what is obtained", which presents the major trend of the current higher education. 


\section{Feasibility of integration of Human Exercise Science and occupation of health manager}

Ever since it was set, Human Exercise Science has cultivated a large number of outstanding sports researchers for Chinese sports science. With the arrival of the great mass fervor of national fitness, the professional curriculum setting of Human Exercise Science and becomes gradually disconnected with social occupational demand, mainly due to the single curriculum mode of university Human Exercise Science, excessive emphasis on basic theory and classroom teaching but little on practical operation and professional practice. Domestic status suggests that most universities don't have a long history of Human Exercise Science, which remains a newly-set profession. On the other hand, the faculty strength is weak and the curriculum provisions and cultivation objective cannot meet the need of employment. In foreign countries, although Human Exercise Science hasn't been particularly named, it is included in vocational education majors as sports \& leisure, sports rehabilitation $\&$ health care and sports medicine. In the training of health manager, an occupation newly released nationally, a considerable fraction of the content overlap the sports rehabilitation and health care. It has provided a very good platform to open up the employment channel of Human Exercise Science and proposed some suggestive thinking for the connection of Human Exercise Science and occupational education.

The development trend of higher education shows that the basic characteristic of talent cultivation is to cultivate multi-layered, diversified and adaptable personnel; the essential feature of talent cultivation standard in the future is multiply fields and a solid foundation; the basic social requirements for talents are inter-disciplinary talents. Guided by this thinking, the talent cultivation standard on Human Exercise Science can be determined as: to cultivate compound talents with all-round development of morality, intelligence, sports and arts, theoretical capacity, practical applying ability and experimental operation skills and are able to be occupied in health education, teaching of sports and health education, research on Human Exercise Science, sports medical health care and the rehabilitation and fitness tutoring in all levels and all types of schools, sports science and technology institutions, exercise training bases and health care and rehabilitation organs.

The first killer threatening human health in the 21 st century is the life style diseases. Currently, the money spent by Chinese people on medical treatment accounts for a high proportion in their living expenses, and it becomes increasingly prominent that Chinese people age before getting rich; on the other hand, they are faced with high healthy risks and take excessive medical treatments. Besides, the average medical resource is insufficient. Health manager is born at the right moment as a new profession. Through health management, the health risk factors of individuals can be controlled and reduced. Health management programs can effectively lower the total number of high-risk people and reduce medical expenses. Considering the characteristic of this occupation, in December 2005, the National Ministry of Labor and Social Security included health manager in the range of special occupations of health care industry.

From the perspective of added value to the value chain, health manager is in fact a health information supplier and the pusher of health promotion. As a health information supplier, health manager must have a certain stock of medical and public hygiene knowledge, which is different from the professional level of medical staff; as a pusher of health promotion, heath manager should have good interpersonal relationship, interpersonal communication skills and the ability to organize and coordinate in communities. 4 Health manager was listed as a knowledge and skill-based occupation from the beginning and considered as a special national profession of the health care industry by the National Ministry of Labor and Social Security. The occupational skill identification and management of health managers are the responsibility of the Occupational Skill Identification Instruction Center of the Ministry of Health, who are suppose to guarantee the quality of health 
managers through strict training, evaluation and identification. Health managers are mainly distributed in medical health care institutions, centers for disease control and prevention, community health service organs and health management companies. Besides, social demand for health managers will increase step by step with the development of Chinese economy. 5

Health managers are professionals that monitor, analyze and evaluate the health condition and diseases of groups or individuals and maintain and promote health. 6 The vocational functions include health monitoring, health risk evaluation and analysis, health guidance, health risk factor intervention and guidance, training and research. The talent cultivation objective and curriculum setting of Human Exercise Science is adjacent to and corresponds to this objective to some extent. Students are required to acquire basic theories and knowledge of Human Exercise Science, sports medicine and science of physical culture and sports, know the identification and evaluation methodology of function of human body, the practical skills of sports health care and rehabilitation and the basic capacity of teaching, scientific research and experimental operation on Human Exercise Science and health education. Hence, Human Exercise Science majors are completely in conformity with the condition of occupational authentication application and have their own specialty superiorities. For instance, they can change the traditional physical examination mode adopted by MECs (medical examination centers) of medical institutions or professional physical examination organizations that focuses only on disease screening but hardly any evaluation of body function status, follow-up sports intervening instructions or other track services. 7

The relationship between physical exercise and physical health and the importance of health management, health intervention \& maintenance and promotion of physical health have been increasingly recognized by the public. Sports behaviors concern public health in its own way and benefit national physique monitoring, health measurement and instruction and so on. Currently, the General Administration of Sport of China and sports bureaus and research institutes of sports science of all provinces, cities, districts and counties have been taking active actions in national physique monitoring, health guidance and instruction and other activities that promote public health and advocate general fitness. By combining sports and hygiene, cooperating with community service and colleges and universities and other characteristic models, tests, evaluations and analysis on elements of individuals' fitness are conducted, and appropriate exercise prescriptions are prepared based on the comprehensive results. Meanwhile, health guidance and intervention should be given during sports, and persistent medical effect follow-ups, evaluation analysis and exercise prescription preparation should also be insisted on. Some fitness clubs provide the public with scientific body-building activities under the guidance of exercise prescriptions, including screenings of body functions, sub-healthy states and other indicators and follow-up tracking service modes. As the society develops, such trend indicates that sports industry and medical and health services can influence and promote each other in many aspects and jointly accomplish the mission of guaranteeing public health.

In order to achieve the goal, in curriculum setting, schools of Human Exercise Science of colleges and universities, in addition to preserving the original features of the discipline, can attach more importance to curriculum module relevant to medicine and health and strive to be all-inclusive, exploit the advantages to the full and enhance the distinctive characteristics. They should also perfect students' knowledge structure and encourage students to take an active part in occupational identification training so that they can give full play to their superiorities and specialties in employment. However, for undergraduate teaching, the practicability and reality should be highlighted. Therefore, the number of jobs available for majors of Human Exercise Science after their education becomes larger and larger. Most graduates flow to organizations of practice, such as 
fitness clubs and health instruction centers. Based on this, undergraduate teaching of Human Exercise Science should be adapted to this social development and change; particular stress should be laid on practical type in talent cultivation and the cultivation of practical talents should be considered as the central task; ensure that students are able to apply knowledge comprehensively and know about various occupational skills; graduates' employment channels should be broadened constantly; practical abilities of undergraduates should be trained, so that they can develop occupational skills and be competent in their jobs after the graduation. 8,9

\section{Existing problems and difficulties}

Although the idea of health management has been widely supported, the national requirement of health maintenance and improvement is increasingly enhanced. The burgeoning health management service has a very broad prospect. Health manager, as a new occupation, lays a human resource foundation for China to form an industry based on health management service. Under the current social background, it is feasible to connect the major of Human Exercise Science and the occupational education of health managers, and certain social effects will be reached based on it. Nevertheless, as a new talent cultivation mode, universities and colleges will inevitably be confronted with all kinds of unexpected problems and difficulties. The success of this new attempt or teaching reform depends on whether we can make a positive and practical response.

(1)Although academic and information exchanges increase in recent years, no professional national coordinate organization of health management has appeared yet, nor has there been any expert team with rich practical experience or rounded health management theoretical system.

(2)Health management is still a rising industry and it is very difficult for health management service organs to run the business or build satisfactory professional practice base. The teaching quality is a big concern too.

(3)Occupational education requires extra expenses for training and identification. The lack of cooperation of training and evaluation centers increases the burden of students and makes it difficult to do promotion in other regions.

(4)Contents of health manager training should be added to the cultivation program, yet its systematicness and practicability depends on the further strict inspection of the employment market on the cultivated talents. Under the combined action, it's usually difficult to distinct the genuine from the false of many complex factors.

\section{Acknowledgment}

This work was teaching reform research project of the Education Committee of Chongqing City (No. 153122), and financially supported by Chongqing Three Gorges University, China.

\section{References}

[1] Occupation Skill Appraisal Center of Employment and Training Department of the Ministry of Labor and Social Security. 2003. National Occupational Skill Identification Course. Beijing Broadcasting Institute Publishing House.

[2] Xue Bai, Shu-li Chen. 2007. Analysis on the Necessity and Countermeasures of College Students' Vocational Education. Journal of Continuing Education Research, 5: 62-63. 
[3] Jing-Jiang Cao, Zhong-Gui Zhu. 2008. Register for Examination of Professional Qualification Certificate and Improving the Competitiveness of College Students' Employment. Journal of Yangtze University(Social Sciences), 31(3): 671-672.

[4]Chao-Hui Xie. 2007. Thinking on Some Problems of Carrying out Health Manager Training. Chin J of Health Management, 7: 489-490.

[5] Jun-Shi Chen, Jian-Shi Huan. 2007. Health Management in China's History, Status quo and Challenges. Chin J General Practice, 6(1): 45-47.

[6] Jun-Shi Chen, Jian-Shi Huan. 2007. Health manager. Chinese Peking Union Medical College Publishing House.

[7] Fang-cai Chen, Li-Li Niu, Han-Hua Wang. 2007. Health Management Promoting Health[J]. Science of Travel Medicine, 13(1): 43-44.

[8] Zhi-Ping Xu, Yu-Qiang Jin. 2008. Health Management and Guiding of Sports-From the First Health Management Specialist and Appraisal Classes to Sports Workers New Jobs. Journal of Jilin Physical Education, 24(2): 18-20.

[9] Qing Yu, Yuan-Ning Pang. 2005.An analysis of job opportunities for college graduates of sports science and kinesiology. Journal of Zhangjiang Normal College, (26)3: 79-83. 